\title{
LA EDITORIAL UNIVERSITARIA Y SU IMPORTANCIA EN EL FORTALECIMIENTO DE LA IDENTIDAD INSTITUCIONAL
}

\author{
Patricia Vilcapuma Vinces* \\ Universidad Católica Sedes Sapientiae
}

ReSUmen: En este breve estudio presentaremos los principales aspectos que configuran una editorial universitaria y analizaremos cómo una adecuada gestión de la editorial contribuye a la consolidación de la identidad institucional. Para ello revisaremos aspectos teóricos que nos permitan analizar y delimitar la función de una editorial universitaria, su relación con la educación universitaria y la identidad institucional. Asimismo, presentaremos los beneficios institucionales que se desprenden de la organización del catálogo como estrategia de administración editorial. Finalmente, comentaremos la experiencia del Fondo Editorial UCSS en relación con lo anteriormente expuesto.

* Patricia Vilcapuma Vinces es Comunicadora Social por la Universidad de San Martín de Porres. Estudia el Diplomado en Formación en la Fe de la Universidad Antonio Ruiz de Montoya. Tiene experiencia en redacción periodística y académica. Actualmente se dedica a la docencia universitaria (lectura literaria, trabajo académico, redacción) y es jefa del Fondo Editorial de la Universidad Católica Sedes Sapientiae. 
Palabras clave: editorial, catálogo, gestión, identidad, educación universitaria, universidad católica

Aвstract: In this brief study we will introduce the main aspects that shape a university editorial and we will analyze how an adequate editorial management contributes to the consolidation of the institutional identity. For this, we will review theoretical aspects that will help us to analyze and delimit the functions of a university editorial as well as its relationship with the university education and the institutional identity. Furthermore, we will present the institutional benefits as a result of the catalog organization which in turn is an editorial management strategy. Finally, the experience of the Fondo Editorial UCSS will be commented in congruence with what was already explained.

KEY worDs: editorial, catalog, management, identity, university education, Catholic university

ecientemente, un diario colombiano publicó una nota con el siguiente título La revolución silenciosa de las editoriales universitarias. a una universidad, en la que se refería, entre otros puntos, a la misión de una editorial universitaria y a su contribución más allá del edificio que la alberga, en cuanto — dice la nota — «tiene la misión de cumplir un servicio público que casi nadie más haría: publicar investigación, ensayos o trabajos doctorales que hacen, muchas veces, avanzar las sociedades en múltiples aspectos o, como es el caso del pensamiento académico, que permiten a un país repensarse a sí mismo. Como la búsqueda no implica afanes de lucro [...] pueden editar aquello que pocos editarían». ${ }^{1}$

1 Morales Thomas, Nicolás. «La revolución silenciosa de las editoriales universitarias. 


\section{LA EDITORIAL UNIVERSITARIA Y SU IMPORTANCIA EN EL FORTALECIMIENTO DE LA IDENTIDAD INSTITUCIONAL}

Efectivamente, las editoriales universitarias, cuya principal labor es la promoción del pensamiento académico que se produce en la Universidad, contribuye a la formación crítica de un país, a la capacidad de enjuiciamiento y a la comprensión de la realidad. Gracias a la labor editorial, la discusión «silenciosa» en las aulas, en los pasillos, entre los maestros, entre maestros y discípulos, ya no se queda exclusivamente entre algunos espacios. Su labor traspasa el momento, y si bien acoge «aquello que pocos editarían», ciertamente acoge, recupera como valor (y casi siempre transforma en novedoso) algo que jamás se agota: lo permanente.

Por otro lado, la edición universitaria y la institución que la alberga tienen una relación estrecha en cuanto a la estatura de esta última. Las publicaciones son un indicador de la actividad intelectual en función y constante de la universidad, que es evaluada por organismos educativos encargados de acreditar la calidad del ejercicio que se imparte en las casas superiores de estudio. En nuestro país, por ejemplo, se tiene el Modelo de Calidad para la Acreditación de Carreras Profesionales Universitarias en el que la edición universitaria tiene un lugar central como parte de las líneas de investigación que se exigen para toda carrera universitaria. ${ }^{2}$

Asimismo,

Hoy por hoy, la producción universitaria es la consecuencia de una fácil identificación del quehacer académico, experimental e

Publicar libros se convirtió en un factor importante a la hora de medir a una universidad». En El Tiempo, diario de Colombia, 30 de abril de 2011. Disponible en: $<$ www.eltiempo.com/entretenimiento/libros/la-revolucion-silenciosa-de-las-editorialesuniversitarias_9244941-4>. Consulta hecha en 21/07/2011. El énfasis es nuestro.

2 Ver Normas legales. Modelo de Calidad para la Acreditación de Carreras Profesionales Universitarias. Disponible en <http://www.unmsm.edu.pe/occaa/publicaciones/ modelo_acreditacion_educacion.pdf>. 
investigativo realizado al interior de la universidad. Es la tarea garante del cumplimiento ético de la calidad pedagógica y científica que persigue la universidad y establece, en gran medida, la imagen institucional que desea proyectar. Es uno de los instrumentos de evaluación que permite saber si la misión se está cumpliendo y si la visión se está haciendo realidad. (Cardona, Serrano y Delvasto 2007: 29, el énfasis es nuestro)

\section{LA EDITORIAL UNIVERSITARIA}

Coincidiendo con Nadal, "la edición es una actividad transversal a las industrias de contenidos, a la educación, a los sectores de economía». De allí la importancia que tiene esta labor en la sociedad; además de la riqueza como producto que se puede generar, la buena edición ayuda a formar conciencia y sentido. Este aspecto es importante cuando se habla de una editorial universitaria, porque hace que se estrechen los vínculos de la universidad con la sociedad.

Aunque el adjetivo universitaria de alguna manera indique su naturaleza, caracterizar una editorial de este tipo no es tan sencillo, como parece evidenciar la afirmación anterior. Algunos expertos resaltan (Rodríguez Castellanos 2004, CERLAC 2006, Cardona, Serrano y Delvasto 2007), en la mayoría de todas las propuestas de definición, su pertenencia a instituciones de educación superior y una relación consustancial en cuanto a la existencia de ambas basada en la complementariedad de la gestión (Cf. Sierra 2005); así como una interacción y, en ocasiones, conflicto, entre la línea editorial, las exigencias económicas y las exigencias del catálogo.

El Centro Regional para el Fomento del libro en América Latina y el Caribe (CERLALC), en el libro Las editoriales universitarias en América 


\section{LA EDITORIAL UNIVERSITARIA Y SU IMPORTANCIA EN EL FORTALECIMIENTO DE LA IDENTIDAD INSTITUCIONAL}

Latina, presenta, mediante un estudio de Leandro de Sagastizábal (Cf. De Sagastizábal, Rama y Uribe 2006), aspectos sobre el quehacer editorial en las universidades que no podemos pasar por alto en la reflexión de nuestra labor. Tomando como referencia los casos de las editoriales universitarias venezolanas, mexicanas y argentinas, De Sagastizábal menciona lo siguiente:

1. Se califica como editoriales universitarias «a aquellas editoriales que pertenecen a las instituciones de educación superior, que cumplen funciones de edición e impresión y que destinan sus productos culturales para uso académico de las mismas y, también, para sectores extra-universitarios» (De Sagastizábal y otros 2006: 101, el énfasis es nuestro)

2. «La editorial universitaria debe ser una empresa, aunque haya nacido del medio universitario y debe cumplir exigencias de racionalidad económica propias de toda compañía si no quiere convertirse en un lastre que tarde o temprano, no podrá ser soportado por la universidad» (Jaramillo ápud De Sagastizábal y otros 2006: 102, el énfasis es nuestro)

3. Dos aspectos constituyen las flaquezas de las editoriales universitarias: a) «Falta de claridad respecto al sentido y la orientación que las universidades acusan acerca del tema editorial»; b) «aplicación de criterios comerciales reduccionistas o meramente mercantiles, que llevan a que no pocas entidades universitarias desvinculen la tarea editorial de la función social y formativa que, se supone, sustentan como proyecto general y permanente» (Loyola ápud De Sagastizábal y otros 2006: 102, el énfasis es nuestro). 
De este panorama quiero resaltar y reflexionar brevemente acerca de tres conceptos: productos culturales, exigencias de racionalidad económica y proyecto general y permanente. Para ello acompañaré mi disertación con la observación que hace Roger Chartier sobre el proceso de publicación: "Sea cual sea su modalidad, siempre es colectivo» (2007: 59).

Si seguimos las palabras de Chartier sobre la actividad de editar, es importante definir a qué tipo de resultado nos referimos con producto cultural, es decir, el libro, y a los factores que intervienen en su realización como trabajo colectivo. Montroni se refiere a este como el instrumento para renovar nuestra cultura, ya que hay «exigencia de leer más, hacer más investigaciones, más análisis, desarrollar intensamente saberes integrados, no limitarse a la excesiva especialización» (Montroni 2007: 7).

Debo anotar que a causa del microcosmos creado tanto por las variadas actividades de carácter intelectual como económicas que rodean al libro, su naturaleza de bien de consumo le da un carácter ambiguo. ${ }^{3}$ Es al mismo tiempo un bien público y un bien privado (Cf. Brunetti, Collesei, Vescov y Sòstero 2005: 1).

En cuanto a lo primero, a decir de Gambaro, el libro es «un vehículo de cultura, de integración y promoción social, un fenómeno artístico o un simple entretenimiento». ${ }^{4}$ Por otro lado, Brunetti y otros consideran al libro como un bien privado «desde el momento en que tiene un mercado propio, en el cual la satisfacción de la demanda por parte de los productores compite con otros libros u otros productores» (2005: 1).

3 Brunetti y otros (2005) añaden que un buen libro admite un precio fijo, aunque este no sea suficiente como para cubrir los costos.

4 En «I confini dell'industria editoriale», en Indagine sull'editoria, Turín Fondazione G. Agnelli. Citado en Brunetti, Collesei, Vescov y Sòstero 2005: 1. 


\section{LA EDITORIAL UNIVERSITARIA Y SU IMPORTANCIA EN EL FORTALECIMIENTO DE LA IDENTIDAD INSTITUCIONAL}

Atendiendo a esta peculiaridad, se pueden añadir otros aspectos que caracterizan al libro y que no debemos olvidar:

- Es principalmente un bien de consumo, pero el hecho de que, una vez leído, sea conservado en bibliotecas familiares y personales, con frecuencia lo hace entrar en la categoría de bien de inversión;

- es un bien que podría considerarse masivo (si pensamos en el fenómeno de los best-sellers), pero en un examen más atento resulta evidente que el libro es un bien que debe insertarse de forma focalizada, dirigida a un segmento de mercado específico, pues el editor realiza la mayor parte de sus ventas a compradores con gustos y necesidades particulares;

- es un bien que satisface una multiplicidad de funciones del comprador-lector, que pueden ser educacionales, culturales y de entretenimiento, $y$

- es, en resumen, un bien que representa características únicas, pues cada título es diferente —es de hecho un prototipo-, aunque puedan distinguirse características homogéneas (genéricas de los libros) (Cf. Gambaro ápud Brunetti y otros 2005: 1-2)

Las editoriales encargadas de convertir un manuscrito en un vehículo de cultura, así difieran en los actores, funciones y necesidades, no están exentas de la racionalidad económica, en cuanto a la naturaleza del producto resultante de este proceso; que requiere indiscutiblemente de una planificación de costos acorde con sus objetivos. Coincidiendo con Woll, «la diferencia [entre las editoriales] reside en el grado de complejidad, no en la naturaleza del problema o de la materia» (2003: XXIV). 
Es así que, en cuanto a la editorial universitaria, como afirman De Sagastizábal y otros, son múltiples las posibilidades en su quehacer y «en muchos casos son específicas para una editorial y difícilmente aplicable a otra» (2006: 103). Y si bien su objetivo principal no es la rentabilidad, el equilibrio entre la planificación y la construcción del catálogo en función de los proyectos que se generen, de acuerdo a su naturaleza universitaria y la misión de la institución educativa que las alberga, es lo deseable.

Si bien no se espera ventas masivas, el tema del «control de mercado» y las miras a una autosubvención deberían estar presentes. A pesar de ello, se debe recordar que su fortaleza está en la naturaleza académica y de investigación científica, y es a eso a lo se debe responder, incluso al momento de planificar en costos. ${ }^{5}$

De hecho que no se puede dejar de lado establecer criterios serios sobre presupuestos al momento de ejecutar un proyecto editorial. He mencionado que un libro, además del valor cultural, es un producto que requiere una inversión, pero una universidad que, apelando al dinero perdido, no apueste por este tipo de ganancia simbólica que generan los productos editoriales universitarios estaría negando su propia naturaleza: la investigación, y estaría poniendo en juego, más que su imagen, el concepto que se tiene - y que debe consolidar — de institución académica universitaria. ${ }^{6}$

Las editoriales universitarias, dice la experiencia y las reflexiones de estudiosos del tema de administración editorial, tienen, en ese sentido, un grado de complejidad al tener como esencia ese carácter único y trascendente

5 Parte de las declaraciones dadas por la autora de este artículo al portal Libros Peruanos. Véase Libros Peruanos. <http://www.librosperuanos.com/editoriales/UCSS.html>. Consulta hecha en 21/07/2011.

6 Ibidem. 
que le da la Universidad como proyecto permanente de interacción con una comunidad académica. La convivencia del valor simbólico, intelectual, del libro y la «racionalidad económica» que se deben considerar suelen marcar el grado de complejidad del que habla Woll, ya que el apego a una visión reduccionista de lo que se entiende por ganancia constituye un peligro para la identidad que debe reforzar la editorial universitaria.

Sabemos que un fondo editorial universitario no es una «editorial comercial», ya que no se espera «agotar el producto» de inmediato. En el caso de un fondo editorial universitario, los ingresos entran lentamente y los libros estan disponibles por una larga temporada. Este aspecto, incluso, puede beneficiar de alguna manera la visibilidad de la institución editorial, ya que contribuye a la presencia efectiva de la universidad en el medio académico.

Para producir libros se necesita un trabajo orientado respecto de los lectores; seguimiento para atraer a los lectores más jóvenes a los volúmenes con esta capacidad de permanecer en el tiempo; atención a la demanda y contenidos de los cursos curriculares, de perfeccionamiento educativo, académicos y profesionales. Como sostiene Furió, una editorial universitaria «aumenta la demanda de una información cada vez más especializada y, al mismo tiempo, de un pensamiento crítico y libre, sólido e independiente; y esta es, precisamente, una de las primeras y más importantes funciones que cumple hoy y que seguirá cumpliendo en el futuro la universidad» (2005: 24).

\section{IDENTIDAD Y LABOR EDITORIAL}

Cada editorial universitaria tiene como punto de partida la experiencia educativa que corresponde a la casa de estudios a la que pertenece. Siguiendo 
a Serra (2005: 20), puedo decir que la editorial universitaria está inmersa en una institución llamada Universidad, cuyo desempeño social tiene tres misiones específicas: la docencia, la investigación y la difusión cultural. Las dos primeras son muy propias de la institución académica, "pero se convierten en materia prima y razón fundamental para que la Editorial se nutra y produzca con base en ellas», y al convertirse en libro o publicación similar el producto de la investigación o las necesidades de la docencia «la editorial es la encargada de cumplir la tercera función de la Universidad: la Difusión Cultural»

Así, coincidiendo con Leandro de Sagastizábal,

El interés por dilucidar los rasgos que caracterizan a una editorial universitaria obedece no sólo a razones de índole metodológicas, sino, también, a que es deseable [nosotros diríamos indispensable] que las editoriales universitarias [...] exhiban una actividad que sea acorde a la filosofía — los principios éticos que sostienen su quehacer—, la visión —su idealización de futuro—, y la misión - la guía de navegación, aquellas principios y mecanismos que se utilizarán para la gestión. (De Sagastizábal y otros 2006: 103)

Un fondo editorial universitario, consideramos, tiene el deber primordial de difundir la investigación realizada por los docentes de las distintas facultades, centros y departamentos académicos que integran la institución, así como los materiales especiales para las cátedras. Todo ello reflejo de su propuesta educativa y que va de la mano con la rigurosidad al momento de seleccionar materiales o decidir si alguno reúne las cualidades para convertirse en libro. 


\section{LA EDITORIAL UNIVERSITARIA Y SU IMPORTANCIA EN EL FORTALECIMIENTO DE LA IDENTIDAD INSTITUCIONAL}

Esta parte del trabajo pone a los fondos editoriales universitarios ante: a) la falta de disciplina al diseñar las colecciones o en la organización del catálogo (Cf. CERLALC 2006: 7-10) y b) la «Infoxicación», que es el resultado negativo de la generación de demanda (Cf. Nadal y García 2005: 40-41) y la publicación de libros malos y mediocres, que terminan por censurar a los buenos; en el caso institucional hablamos de «una producción para "figurar" más que para aportar al debate público».?

Respecto a la primera situación que señalo, debido a la interdisciplinariedad que es parte de la convivencia universitaria, las publicaciones están al orden del día y cada departamento tiene sus propios requerimientos (contenido, formato, publicidad, promoción, etc.), y el fondo editorial es ante todo un órgano ejecutor. Cuesta, en algunas ocasiones, mucha fe en el oficio para no perder la paciencia y a la vez conseguir al menos un acercamiento a la ansiada coherencia del catálogo (Cf. Davies 2005: 147-152).

En cuanto a la segunda, Jordi Nadal toma este concepto clave, la infoxicación, para referirse al exceso casi malsano de «editar por editar». Nadal explica muy acertadamente que «el exceso de oferta crea una desconfianza en la demanda, porque confunde [...] No estaría mal recordar que es inadmisible editar libros que no se han leído. No es ni rentable ni culturalmente sano» (Nadal 2005: 39).

En el caso institucional, como he señalado, esta infoxicación a la que está expuesta la edición universitaria trasciende el plano del libro mediocre. Si se ha coincidido que la Universidad por naturaleza es un centro de debate y generación de conocimiento en la sociedad, y la labor editorial que parta

7 Silva Santisteban, Rocío. "Alas y buen viento». Columna Okupa del diario La República, 6 de diciembre de 2009. Disponible en <www.larepublica.pe/columnistas/ kolumna-okupa/alas-y-buen-viento-06-12-2009>. Consulta hecha en 21/07/2011. 
de este tipo de institución es, por ende, el reflejo de su trabajo intelectual, caer en una producción "por figurar» perjudicaría seriamente la identidad que proyecta una casa académica universitaria.

Esta edición «por figurar» que percibe la crítica y la comunidad académica se refiere a publicaciones patrocinadas por universidades y que aparentemente no tienen relación con los programas académicos que se imparten. Esto es discutible hasta cierto punto, ya que el debate e investigación propios del trabajo intelectual generan apertura; por eso es normal que las universidades abran sus puertas a investigadores y propuestas que dialoguen con el quehacer académico de sus aulas. Asimismo, el patrocinio a intelectuales, artistas y otros que tengan aportes para la comunidad merecen el apoyo no solo de universidades sino de instituciones en general.

En el caso de una universidad convendría, pues, tener en claro que el catálogo es el medio de comunicación de la editorial. Lo que comunica el catálogo acerca de esta experiencia de editar en y para la universidad, es la coherencia entre lo publicado y la identidad de la universidad.

Las universidades, como centros de producción y difusión de conocimientos, deben estar en condiciones de constituirse como la principal fuente de producción editorial, para su propio consumo y para el de la sociedad. Su capacidad de generar contenidos de calidad está ligada a su actuación académica; lo que significa que habría un correlato entre sus logros en el terreno de la edición editorial y «la calidad de su ejercicio académico y de la investigación científica que realiza». (De Sagastizábal 2006: 101, el énfasis es nuestro) 
Organizar el catálogo con esta coherencia se vuelve fundamental. Así, definitivamente, la prioridad está en la investigación y discusión académica generada por la libre y desinteresada búsqueda de conocimiento. En este aspecto deberíamos detenernos para esclarecer algunos puntos sobre nuestro rumbo en el quehacer editorial universitario.

\section{Cuidado de edición y labor educativa}

Si recordamos a Chartier sobre la actividad de editar, ya hemos expuesto la naturaleza ambigua del libro: un producto cultural y un producto privado. No obstante, al insertarse en el circuito editorial universitario la primacía debe estar en su naturaleza de producto cultural, en cuanto el libro está vinculado con la investigación, la docencia y la difusión de cultura. El desaparecido educador Constantino Carvallo decía que: «Hay una relación muy estrecha entre cultura y educación. Por un lado, la educación tiene como misión central la transmisión de la cultura y, por el otro, la construcción de ciudadanos capaces de enriquecer creativamente esta misma cultura» (Carvallo 2006: 25).

Así, es reconocido en nuestro país que las mejores publicaciones pertenecen a las editoriales universitarias ${ }^{8}$ y que gracias al trabajo que realizan en favor de la difusión del pensamiento intelectual han ampliado

8 Véase al respecto «Inquisiciones. Algunas paradojas más una insoportable levedad», columna del crítico literario Abelardo Oquendo, en la que reflexionaba sobre el incremento de las editoriales y la labor realizadas por las editoriales o fondos universitarios: «Y, finalmente, existe un incremento de fondos editoriales universitarios e institucionales. Ya que no dinero, lo que persiguen estos últimos es prestigio [...] De hecho, los mayores aportes bibliográficos a nuestra cultura se deben en las últimas décadas a las ediciones universitarias e institucionales». En La República, diario de Perú, 30 de enero de 2007. Consulta hecha en 21.07.2011. 
su potencial público lector; en otras palabras, las editoriales también son promotoras de lectura.

Si el mercado directo es la propia comunidad académica, y el propósito esencial es demostrar y difundir lo que se investiga o produce desde el campo intelectual, este margen ha sido ampliado a un público mayor, a un público que suele ir a librerías, que lee diarios o alguna revista en busca de novedades, que no está en un círculo determinado por la cofradía usual de la intelectualidad. Los fondos editoriales de las universidades surgen a partir de esta constatación. ${ }^{9}$

Por otro lado, el compromiso con la comunidad académica y el país en general está implícito en la visión que le otorga el carácter universitario de su gestión. ${ }^{10}$ Este aspecto del trabajo editorial universitario lo recordaba Ismael Pinto, director del Instituto de Investigaciones de la Facultad de Ciencias de la Comunicación de la USMP:

Soy consciente de que la Universidad San Martín de Porres suple las carencias culturales del país, carencias que debería asumir el Estado. Nuestro fin no es ganar dinero con las publicaciones. El motivo principal es difundir cultura y rescatar importantes trabajos o textos que por falta de iniciativa no se publicarían en

9 Izquierdo Quea, Francisco. «Publicaciones emergentes. El detrás de fondos editoriales universitarios». En El Hablador, N. 8, 2005. Disponible en <www.elhablador.com/ publica1.htm>. Consulta hecha en 21/07/2011.

10 Al respecto véase Picón 2006: 26: «Las universidades afrontan el reto de la difusión de escritores, especialistas e investigadores de diversas disciplinas, a través de las publicaciones producidas por sus fondos editoriales. Una larga lista de casas de estudio, entre ellas, las universidades de Lima, del Pacífico, Ricardo Palma, de Ciencias Aplicadas, Católica, San Marcos, San Martín, Sedes Sapientiae, entre otras demuestran su compromiso con el conocimiento». 


\section{LA EDITORIAL UNIVERSITARIA Y SU IMPORTANCIA EN EL FORTALECIMIENTO DE LA IDENTIDAD INSTITUCIONAL}

otras instituciones: poner el libro al alcance de la comunidad. Por ello representamos algo diferente y no buscamos sólo lo lucrativo. ${ }^{11}$

Ricardo Silva Santisteban, catedrático y encargado por mucho tiempo de las ediciones del Rectorado de la PUCP, señalaba uno de los distintivos del trabajo de edición propio de una editorial de carácter académico universitario. "Nuestra política se centra en rescatar obras de autores que nadie reedita o publica. Es común que se piense en regalías, en las ventas. No tengo nada en contra de eso, pero el objetivo de las ediciones que elaboramos es dar a conocer las grandes obras literarias peruanas y universales poco conocidas, y además, llenar un vacío [...] presentando libros útiles a los lectores y académicos» (ápud Picón 2006: 27).

Asimismo, el crítico Abelardo Oquendo, al comparar la repercusión de la experiencia editorial universitaria con la de una comercial, señala que «la significación cultural de lo publicado por los sellos comerciales es pequeña». ${ }^{12}$ Por ello, si bien «la universidad es lo que publica», como reza el lema del Fondo Editorial de la Universidad Nacional Mayor de San Marcos, decana de América, concuerdo con Biagio D’Angelo, exdirector del Fondo Editorial de la Universidad Católica Sedes Sapientiae, un país es lo que publica:

[...] Nosotros creemos fuertemente que el desarrollo de la cultura en nuestro país nace de una producción editorial seria y consciente, de la divulgación de autores, experiencias, textos que pertenecen no exclusivamente a la cultura peruana, sino a la

11 Izquierdo Quea, Francisco, op. cit. 12 OQuendo, op. cit. 
latinoamericana en general. Por lo tanto, diríamos que «el país es lo que se publica», en una ampliación no superficial que abarca contextos, historias y tradiciones. (D’Angelo 2004: 74)

\section{El catálogo como comunicador}

Jorge Herralde de Anagrama afirma acertadamente que el catálogo es el activo simbólico más importante de una editorial. Asimismo añade que un editor es quien coloca un micrófono y altavoz al catálogo. ${ }^{13}$ Analizando sus palabras y el ámbito en el que se inserta el catálogo de un fondo editorial universitario, podemos deducir que este es la carta de presentación de la universidad en la comunidad a la que pertenece.

De alguna manera, un fondo editorial universitario es una editorial especializada, porque responde a las necesidades de estudio claramente definidas por el nivel del lector, el carácter dialógico intelectual de una casa superior de estudios y por la orientación que marca la misión y visión de la institución. La especialización puede significar una reducción en el mercado de lectores, pero la buena comunicación de la coherencia de la propuesta puede construir y consolidar una amplia categoría de lectores dentro de su especialidad como casa editora universitaria.

El catálogo de un fondo editorial universitario, en general, se organiza a partir de tres aspectos. El primero es el lector, que en nuestro caso es universitario, intelectual, profesional. El segundo está relacionado a la identidad de la institución que alberga a la editorial, la cual facilita definir la base sobre la cual desarrollar los proyectos editoriales y estimar

13 Véase, además de Nadal y García 2005, la entrevista a Herralde "No soy un héroe de la edición", disponible en el portal mexicano Milenio <http://impreso.milenio.com/ node/8088456>. Consulta hecha en 21/07/2011. 
la justificación de la presencia de un nuevo libro. El tercero es el tema, que forma la familia de libros que guardan relación entre sí.

Las profesiones ofrecidas en las instituciones académicas universitarias, el nivel de lectores, así como los distintos departamentos que integran las facultades y los que son parte de la universidad constituyen una fuente de diversidad que puede aparentemente volver confusa la organización del catálogo. No obstante, es preciso recordar el principio que como bien cultural los libros forman un universo con muchos niveles de lectores potenciales y que los catálogos surgen justamente de esta diversidad.

Por ejemplo, el fondo editorial de la Universidad del Pacífico tiene una serie de libros denominada "Apuntes de estudio», destinada a estudiantes del pregrado y resultado de los materiales preparados en las cátedras que imparten en sus carreras; los temas que abarca son variados, van desde los cursos de humanidades hasta los de empresa. Asimismo, publica otros títulos que están dirigidos a profesionales.

El catálogo de un fondo editorial universitario tiene de por sí una coherencia y una identidad: las universidades investigan y publican por naturaleza. Su misión primordial es contribuir a la formación humana en general.

Entonces, una adecuada gestión del catálogo cobra importancia por dos aspectos:

- La consolidación de una experiencia, sobre todo si es que vamos a empezar a ordenar nuestras publicaciones. Si ya estamos en camino, la contribución que se hará al entorno institucional es fundamental: además de aportar prestigio a la institución, le daría una identidad más sólida a la editorial, marcaría su diferencia con las otras. 
- La generación de oportunidades de a) crear otras colecciones con la solvencia de la experiencia ganada (por ejemplo, que reúna las patrocinadas, los libros de protocolo o regalo para invitados conferencistas, o las ediciones especiales); b) enriquecer la colección que es producto del debate académico institucional propio con aportes extrauniversitarios; c) desarrollar una posible colección original, única, que otros fondos editoriales no hayan detectado, a pesar de que las instituciones coincidan en propuestas académicas. Y otras oportunidades que la revisión de la experiencia propia, la investigación, el análisis, el seguimiento, puedan generar.

\section{LA EXPERIENCIA DEL FONDO EDITORIAL UCSS}

En septiembre del año 2000, fecha en que se celebró la apertura oficial de nuestro primer año académico, también se presentó nuestra primera publicación, la revista Studium Veritatis, cuyo nombre recordaba el punto de partida de nuestro quehacer universitario: pasión por la búsqueda desinteresada de la verdad, de lo bello y de lo justo, del sentido último del hombre (Martínez Valls 2010: 1-6).

Siendo «hijo» de una universidad católica, la labor del Fondo Editorial UCSS se enriquece de «la experiencia tan amplia y fecunda de la Iglesia en el sector universitario y abierta a las realizaciones prometedoras del porvenir, el cual exige audaz creatividad y al mismo tiempo rigurosa fidelidad» (Juan Pablo II 1990). ${ }^{14}$ En una Universidad Católica, como señala la Constitución Apostólica Ex Corde Ecclesiae, nuestra carta magna,

14 Ex Corde Ecclesiae. Constitución apostólica del Sumo Pontifice Juan Pablo II sobre las Universidades Católicas (1990). Publicación organizada y editada por el Área de Comunicación y Producción del Lenguaje del pregrado y difundida mediante la Pastoral Universitaria de la Universidad Católica Sedes Sapientiae, 2007, p. 8. 


\section{LA EDITORIAL UNIVERSITARIA Y SU IMPORTANCIA EN EL FORTALECIMIENTO DE LA IDENTIDAD INSTITUCIONAL}

la investigación abarca necesariamente a) la consecución de una integración del saber, b) el diálogo entre fe y razón, c) una preocupación ética y d) una perspectiva teológica. ${ }^{15}$

Así, nace el Fondo Editorial de la Universidad Católica Sedes Sapientiae, como espacio correspondiente a la labor realizada en la institución que la alberga, "donde la relación de fe y cultura encuentra su sentido y significado». ${ }^{16}$ A partir de ello, la importancia de nuestra labor editorial en el entorno universitario asume un matiz especial; «su inspiración cristiana le permite incluir en su búsqueda, la dimensión moral, espiritual y religiosa, y valorar las conquistas de la ciencia y la tecnología en la perspectiva de la persona humana». ${ }^{17}$

Por otro lado, concordando con una idea de Aristóteles, consideramos que la riqueza está en el uso más que en la propiedad. $Y$ es en el uso de nuestras capacidades de fomento de investigación y de creación, a la luz de nuestra fe cristiana, donde se encuentra la esencia del espíritu universitario, el mismo que une tanto a profesores, estudiantes y autoridades en este "proceso colectivo", que bien señalaba Roger Chartier al definir la labor de editar libros. Estos son, a su vez, productores, transformadores y recreadores de ideas (y no meros consumidores culturales) que con su apertura al trabajo académico hacen posible una verdadera experiencia de Universitas. $^{18}$

En estos más de diez años de camino, la UCSS ha publicado más de 70 estudios, testimonios y discusiones en torno a Literatura, Arte,

15 Ibidem, p. 15.

16 Ibidem, p. 6

17 Ibidem, p. 7.

18 Discurso de presentación del Catálogo del Fondo Editorial UCSS. Disponible en Portal Universidad Católica Sedes Sapientiae. <www.ucss.edu.pe/fondo/fondo_presentacion. html>. Consulta hecha en 21/07/2011. 
Lingüística, Historia, Teología, Administración, Derecho, Educación, en fin, todas aquellas disciplinas relacionadas al hombre y su realidad, y que son motivo de reflexión en las profesiones que ofrece.

Actualmente, la gestión de nuestro catálogo se sustenta básicamente en las siguientes líneas:

- Patrística

- Literatura y formación

- Arte y patrimonio

- Educación

- Administración de empresas

- Administración pública

- Ediciones especiales.

En cuanto a publicaciones periódicas se editan las siguientes: Studium Veritatis, que reúne trabajos multidisciplinarios; Cuadernos Literarios, revista de investigación y creación literaria; Riesgo de Educar, revista de la Facultad de Ciencias de la Educación y Humanidades, acompañado de un suplemento. Todas son de periodicidad anual.

En nuestra experiencia hemos entendido que un fondo editorial debería cubrir cierta bibliografía que no hay y, sobre todo, que se haga accesible en costo al público universitario, es decir, existe, por nuestra parte, una preocupación que los estudiantes, y en general que un universitario, pueda comprar los libros e ir armando su propia biblioteca con un material bien hecho, original y con muy buenos contenidos. Pero también hemos entendido que debemos procurar no obviar la correspondencia de las propuestas que llegan a la mesa de edición con nuestro catálogo y, por supuesto, como cualquier otro fondo editorial, procurar realizar un arbitraje o juicio crítico sobre los contenidos por 


\section{LA EDITORIAL UNIVERSITARIA Y SU IMPORTANCIA EN EL FORTALECIMIENTO DE LA IDENTIDAD INSTITUCIONAL}

publicar. Así lucharemos contra el exceso de libros que terminan por opacar lo bueno que vamos consolidando, y que debilitan la identidad editorial y la institucional.

Por otra parte, como departamento académico universitario una de nuestras preocupaciones es cuidar que la producción académica se presente de forma correcta, ya que constituye la principal fuente de difusión del trabajo de investigación de la universidad. Por ello, hemos reunido en el Manual de estilo del Fondo Editorial de la Universidad Católica Sedes Sapientiae (2008) ${ }^{19}$ una serie de normas, que se basan en nuestra experiencia editorial, para ayudar a los autores en la presentación de sus trabajos, y a los correctores y editores a cuidar el estilo de las publicaciones.

Asimismo, estevolumen es una herramienta para la producción de textos que circulan en nuestra universidad; en ese sentido, proponer un «manual de estilo» también responde a un acompañamiento en el trabajo del mejoramiento continuo de la comunicación escrita de la comunidad universitaria y, en suma, un aporte a la labor educativa profesional de la institución. ${ }^{20}$

Finalmente, las publicaciones del Fondo editorial de la Universidad Católica Sedes Sapientiae son muestra de una propuesta educativa leal a su tradición como institución católica, promotora de un «gozo por la verdad», que cada año inicia siguiendo su deseo de corresponder a lectores activos, autónomos, capaces de una apertura total y dispuestos a dejarse acompañar en este trabajo que va más allá del placer intelectual, y que se resume en una actividad constante, a decir de Benedicto XVI, el «ensanchar la razón».

19 Actualizado en el 2010. Disponible en el portal institucional de la Universidad Católica Sedes Sapientiae. <http://www.ucss.edu.pe/fondo/fondo_presentacion.html>.

20 Una de las actividades realizadas por el Fondo Editorial UCSS con la finalidad de contribuir al cuidado de la escritura a nivel institucional y de la comunidad en general es el Curso de Ortografía y Redacción. 


\section{CONCLUSIONES}

1. La actividad editorial es un quehacer ligado a la vida universitaria, por lo que un fondo editorial universitario es el reflejo del compromiso de la universidad con la promoción del pensamiento académico y la investigación; en otras palabras de su misión y visión.

2. La producción editorial universitaria, al estar íntimamente ligada a la política cultural que desarrolla la universidad, establece en gran medida la imagen institucional que como entidad académica desea proyectar.

3. La gestión adecuada del catálogo de una editorial universitaria cobra importancia por dos aspectos: la consolidación de una experiencia educativa y la generación de oportunidades de renovación constante de sus líneas de conocimiento y divulgación.

4. Un catálogo adecuadamente gestionado es «la voz» de la editorial universitaria y, por ende, de la universidad que la alberga. Por ello, debe priorizar la divulgación del quehacer intelectual de los profesionales que acoge y cuidar la pertinencia de los contenidos en relación a la misión y visión de la universidad.

5. En ese sentido, una editorial universitaria católica debe tener como líneas base las mismas de una universidad católica, en la cual la investigación abarca necesariamente: a) la consecución de una integración del saber, b) el diálogo entre fe y razón, c) una preocupación ética y d) una perspectiva teológica (Ex Corde Ecclesiae). 
LA EDITORIAL UNIVERSITARIA Y SU IMPORTANCIA EN EL FORTALECIMIENTO DE LA IDENTIDAD INSTITUCIONAL

Anexo

Publicaciones de la Universidad Católica Sedes Sapientiae

\begin{tabular}{|c|c|c|c|}
\hline Tema & & Título & Autor \\
\hline \multirow{3}{*}{\multicolumn{2}{|c|}{ Patrística }} & $\begin{array}{l}\text { Santo Tomás de Aquino. El } \\
\text { Maestro. Suma Teológica }\end{array}$ & \multirow{3}{*}{$\begin{array}{l}\text { P r e s e n t a c i ó n, } \\
\text { anotación y traducción } \\
\text { de Julio Picasso Muñoz }\end{array}$} \\
\hline & & $\begin{array}{l}\text { San Ambrosio. Los deberes. } \\
\text { Los himnos }\end{array}$ & \\
\hline & & Boecio. Tratado de Música & \\
\hline \multirow{2}{*}{$\begin{array}{l}\text { Literatura } \\
\text { Formación }\end{array}$} & & $\begin{array}{l}\text { Adolescentes en la ciudad. } \\
\text { Una visión de la narrativa } \\
\text { peruana del siglo XX }\end{array}$ & Jorge Eslava \\
\hline & & $\begin{array}{l}\text { Las babas del sabio. Ensayos } \\
\text { sobre la dislocación de la } \\
\text { escritura }\end{array}$ & Biagio D’Angelo \\
\hline \multirow{3}{*}{\multicolumn{2}{|c|}{ Filosofía }} & $\begin{array}{l}\text { Formas de epistemología } \\
\text { moderna }\end{array}$ & Paolo Musso \\
\hline & & Letras de Derrida & Biagio D’Angelo (org.) \\
\hline & & Belleza y realidad & Varios autores \\
\hline \multirow{3}{*}{\multicolumn{2}{|c|}{$\begin{array}{l}\text { Arte } \\
\text { Patrimonio }\end{array}$}} & $\begin{array}{l}\text { Arquitectura prehispánica } \\
\text { tardía: construcción y poder } \\
\text { en los Andes centrales }\end{array}$ & $\begin{array}{l}\text { Kevin Lane y Milton } \\
\text { Luján (eds.) }\end{array}$ \\
\hline & & $\begin{array}{ll}\text { Arquitectura } & \text { virreinal } \\
\text { religiosa de Lima } & \\
\end{array}$ & $\begin{array}{l}\text { Antonio San Cristóbal } \\
\text { Sebastián }\end{array}$ \\
\hline & & $\begin{array}{l}\text { Pasado, presente y futuro de } \\
\text { Lima Norte }\end{array}$ & $\begin{array}{l}\text { José Antonio Benito } \\
\text { (org.) }\end{array}$ \\
\hline
\end{tabular}




\begin{tabular}{|c|c|c|}
\hline \multirow{3}{*}{ Educación } & $\begin{array}{l}\text { El eslabón del día. Ensayos } \\
\text { sobre educación }\end{array}$ & Carlos Gatti \\
\hline & $\begin{array}{l}\text { El sujeto ausente. Educación } \\
\text { entre nihilismo y memoria }\end{array}$ & Massimo Borghesi \\
\hline & Educar es un riesgo & Luigi Giussani \\
\hline \multirow{5}{*}{$\begin{array}{l}\text { Administración } \\
\text { de empresas }\end{array}$} & Estrategia y Proyecto & Antonello Bove \\
\hline & $\begin{array}{l}\text { Responsabilidad social y } \\
\text { resultado de empresa. Hacia } \\
\text { una síntesis sociocompetitiva }\end{array}$ & $\begin{array}{l}\text { Mario Molteni y Elena } \\
\text { Rossato }\end{array}$ \\
\hline & $\begin{array}{l}\text { El desafío del comercio justo } \\
\text { en América Latina }\end{array}$ & $\begin{array}{l}\text { Stefania Mitiga, Laura } \\
\text { Sonjans y Clara Caselli }\end{array}$ \\
\hline & $\begin{array}{l}\text { Perú: tradición textil y } \\
\text { competitividad internacional }\end{array}$ & William Muñoz \\
\hline & $\begin{array}{l}\text { Crecer desde nuestros } \\
\text { límites: un encuentro con } \\
\text { Lima Norte }\end{array}$ & William Muñoz \\
\hline \multirow{3}{*}{$\begin{array}{l}\text { Administración } \\
\text { pública }\end{array}$} & $\begin{array}{l}\text { Serie de Investigación: } \\
\text { Políticas innovadoras para la } \\
\text { administración pública }\end{array}$ & $\begin{array}{l}\text { Centro de Investigación } \\
\text { y Desarrollo Innovador } \\
\text { para la Regionalización }\end{array}$ \\
\hline & $\begin{array}{l}\text { La descentralizacion y sus } \\
\text { instituciones }\end{array}$ & Luis Elguera Valega \\
\hline & $\begin{array}{l}\text { Desarrollo económico local y } \\
\text { subsidiariedad: en búsqueda } \\
\text { de buenas prácticas }\end{array}$ & $\begin{array}{l}\text { Elena Zuffada y Lorna } \\
\text { Beretta }\end{array}$ \\
\hline
\end{tabular}




\begin{tabular}{|c|c|c|}
\hline \multirow{4}{*}{$\begin{array}{l}\text { E d i c i o n e s } \\
\text { especiales }\end{array}$} & $\begin{array}{l}\text { Plutarco. Cómo el joven } \\
\text { debe leer los poemas/San } \\
\text { Basilio. A los jóvenes sobre la } \\
\text { manera de sacar provecho de } \\
\text { la literatura griega }\end{array}$ & $\begin{array}{l}\text { Pres e n t a c i ó n, } \\
\text { anotación y traducción } \\
\text { de Julio Picasso Muñoz }\end{array}$ \\
\hline & $\begin{array}{l}\text { José de Orejón y Aparicio. } \\
\text { La música y su contexto }\end{array}$ & $\begin{array}{l}\text { Diana } \quad \text { Fernández } \\
\text { Calvo }\end{array}$ \\
\hline & $\begin{array}{l}\text { Plumas del Antisuyo. } \\
\text { Vilcabamba, raíz y piedra }\end{array}$ & Ricardo Wiesse \\
\hline & Virgilio. La Eneida & $\begin{array}{l}\text { Prese n t a c i ó n, } \\
\text { anotación y traducción } \\
\text { de Julio Picasso Muñoz }\end{array}$ \\
\hline
\end{tabular}

\section{Revistas}

\begin{tabular}{|l|l|l|}
\hline \multirow{3}{*}{ Revistas } & Studium Veritatis & N. 15 (2011) \\
\cline { 2 - 3 } & $\begin{array}{l}\text { Cuadernos Literarios. } \\
\text { Revista de creación e } \\
\text { investigación literaria }\end{array}$ & N. 9 (2011) \\
\cline { 2 - 3 } & $\begin{array}{l}\text { Riesgo de Educar. Revista de } \\
\text { la Facultad de Ciencias de la } \\
\text { Educación y Humanidades }\end{array}$ & N. 10 (2011) \\
\hline
\end{tabular}


PATRICIA VILCAPUMA VINCES

\section{PUBLICACIONES DIVERSAS}

\begin{tabular}{|c|c|}
\hline Título & Autor \\
\hline 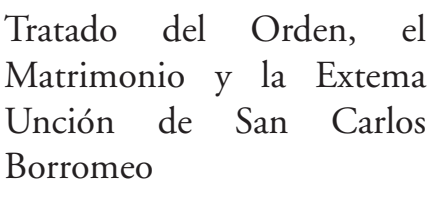 & Mario Grignani \\
\hline $\begin{array}{l}\text { El sentido religioso. Curso } \\
\text { básico de Cristianismo } 1 \\
\text { (coedición) }\end{array}$ & Luigi Giussani \\
\hline $\begin{array}{l}\text { Los orígenes de la pretensión } \\
\text { cristiana. Curso básico de } \\
\text { Cristianismo } 2 \text { (coedición) }\end{array}$ & Luigi Giussani \\
\hline $\begin{array}{l}\text { Por qué la Iglesia. Curso } \\
\text { básico de Cristianismo } 3 \\
\text { (coedición) }\end{array}$ & Luigi Giussani \\
\hline Se puede vivir así (coedición) & Luigi Giussani \\
\hline $\begin{array}{l}\text { El camino a la verdad es una } \\
\text { experiencia (coedición) }\end{array}$ & Luigi Giussani \\
\hline Padre Pío: su voz, su historia & Filippo Anastasi \\
\hline $\begin{array}{l}\text { El Papa peregrino. } \\
\text { Recopilación de escritos por } \\
\text { los } 25 \text { años de su pontificado }\end{array}$ & Varios autores \\
\hline $\begin{array}{l}\text { Crisol de lazos solidarios: } \\
\text { Santo Toribio de Mogrovejo }\end{array}$ & $\begin{array}{l}\text { José Antonio } \\
\text { Benito }\end{array}$ \\
\hline
\end{tabular}




\begin{tabular}{|l|l|}
\hline $\begin{array}{l}\text { Amazonia, un río de palabras. } \\
\text { Estudios sobre literatura y } \\
\text { cultura de la Amazonia }\end{array}$ & $\begin{array}{l}\text { Biagio D'Angelo y Maria } \\
\text { Antonieta Pereira (orgs.) }\end{array}$ \\
\hline $\begin{array}{l}\text { Virgilio. Bucólicas y } \\
\text { Geórgicas }\end{array}$ & Traducidas por Julio Picasso \\
\hline $\begin{array}{l}\text { La nave de los pícaros. } \\
\text { Investigaciones sobre la } \\
\text { novela picaresca }\end{array}$ & $\begin{array}{l}\text { Fernando Rodríguez } \\
\text { Mansilla }\end{array}$ \\
\hline $\begin{array}{l}\text { Comparación y sentido. } \\
\text { Varias Focalizaciones y } \\
\text { convergencias literarias }\end{array}$ & Wladimir Krysinski \\
\hline $\begin{array}{l}\text { Lo propio y lo ajeno. } \\
\text { Ensayos de literatura } \\
\text { comparada }\end{array}$ & Tania Carvalhal \\
\hline $\begin{array}{l}\text { Confluencias e } \\
\text { intercambios. La literatura } \\
\text { comparada y el Perú hoy }\end{array}$ & Biagio Dangelo (ed.) \\
\hline $\begin{array}{l}\text { Verdades y veredas de Rosa. } \\
\text { Ensayos sobre la narrativa de } \\
\text { João Guimarães Rosa }\end{array}$ & Biagio Dangelo (ed.) \\
\hline $\begin{array}{l}\text { Haroldo de Campos, don de } \\
\text { poesía }\end{array}$ & $\begin{array}{l}\text { Lisa Block de Behar } \\
\text { (coord.) }\end{array}$ \\
\hline $\begin{array}{l}\text { Más allá del estepa. Viajes, } \\
\text { utopías y caprichos de la } \\
\text { historia }\end{array}$ & Biagio D'Angelo \\
\hline $\begin{array}{l}\text { Miradas cruzadas: sobre } \\
\text { la literatura italiana } \\
\text { entre modernidad y } \\
\text { postmodernidad }\end{array}$ & Biagio D’Angelo y \\
\hline Assumpta Camps \\
\hline
\end{tabular}


PATRICIA VILCAPUMA VINCES

\begin{tabular}{|l|l|}
\hline Galileo. Mito y realidad & $\begin{array}{l}\text { Coordinación de Giovanni } \\
\text { Sandoval y } \\
\text { traducción de Julio Picasso. }\end{array}$ \\
\hline $\begin{array}{l}\text { Toribio Alfonso de } \\
\text { Mogrovejo (España 1538- } \\
\text { Perú 1606) Documentos } \\
\text { de una excepcional aventura } \\
\text { humana }\end{array}$ & José Antonio Benito y otros \\
\hline $\begin{array}{l}\text { Camino a Damasco. } \\
\text { El inicio de una vida } \\
\text { nueva }\end{array}$ & Varios autores \\
\hline $\begin{array}{l}\text { El Señor de los Milagros. El } \\
\text { rostro de un pueblo }\end{array}$ & José Antonio Benito y otros \\
\hline
\end{tabular}




\section{LA EDITORIAL UNIVERSITARIA Y SU IMPORTANCIA EN EL FORTALECIMIENTO DE LA IDENTIDAD INSTITUCIONAL}

\section{BIBLIOGRAFÍA}

\section{Benedicto XVI}

2006 Fe, razón y universidad. Recuerdos y reflexiones. Discurso de Ratisbona, 12 de setiembre. Disponible en <www.ssbenedictoxvi.org/mensaje. php?id=366>.

Brunetti, Giorgio; Umberto Collesei; Tiziano Vescovi y Ugo Sòstero 2005 La librería como negocio. Economía y administración. México, D. F.: Fondo de Cultura Económica.

Cardona, Teresa; José Julián Serrano y Gustavo Adolfo Delvasto 2007 Políticas editoriales. Santiago de Cali: Universidad Santiago de Cali.

Carvallo, Constantino

2006 «El ministerio más importante para la cultura es el de economía». Gaceta Cultural del Perú, INC, julio, 2006, N. 21, p. 25. Lima.

DAVIES, Gill

2005 Gestión de proyectos editoriales. Cómo encargar y contratar libros. México, D. F.: Fondo de Cultura Económica.

D’Angelo, Biagio

2004 Presentación del libro José Jiménez Borja. Crítico y maestro de lengua. Riesgo de Educar, revista de la Facultad de Ciencias de la Educación y Humanidades de la Universidad Católica Sedes Sapientiae, año 1, N. 1, pp. 74-76. 
FurIó, Antonio

2005 «El futuro de la edición universitaria». En Esencia, quehacer y retos de la edición académica. Memoria del I Foro Internacional del libro de Guadalajara. México, D. F.: Universidad de Guadalajara, Asociación de Editoriales Universitarias, Red Nacional Altexto, pp. 9-24.

IzQuierdo QueA, Francisco

2005 «Publicaciones emergentes. El detrás de fondos editoriales universitarios». En El Hablador, N. 8. Disponible en <www. elhablador.com/publica1.htm>. Consulta hecha en 21.07.2011.

Juan Pablo II

2007 [1990] Ex Corde Ecclesiae. Constitución apostólica del Sumo Pontifice Juan Pablo II sobre las universidades católicas. Lima: Universidad Católica Sedes Sapientiae.

Libros Peruanos

2010 «La primera universidad de Lima Norte y su fondo editorial». Entrevista a Patricia Vilcapuma Vinces, Responsable del Fondo Editorial de la Universidad Católica Sedes Sapientiae. Por Virginia Vilchez. En Libros Peruanos. <www.librosperuanos.com/editoriales/ UCSS.html>. Consulta hecha en julio de 2011.

Martínez Valls, Joaquín

2010 «Diez años de Studium Veritatis». Studium Veritatis, año 8, N. 14, pp. 11-16. 
LA EDITORIAL UNIVERSITARIA Y SU IMPORTANCIA EN EL FORTALECIMIENTO DE LA IDENTIDAD INSTITUCIONAL

Morales Thomas, Nicolás

2011 «La revolución silenciosa de las editoriales universitarias. Publicar libros se convirtió en un factor importante a la hora de medir a una universidad». En El Tiempo, diario de Colombia, 30 de abril. Disponible en <www.eltiempo.com/entretenimiento/libros/larevolucion-silenciosa-de-las-editoriales-universitarias_9244941-4>. Consulta hecha en 21/07.

NADAL, Jordi y Francisco García

2005 Libros o velocidad. Reflexiones sobre el oficio editorial. México, D. F.: Fondo de Cultura Económica.

Picón, José Carlos

2006 «Fondos editoriales de las universidades. Facultad de papel». Gaceta Cultural del Perú, INC, junio, 2006, N. 20, pp. 26-27. Lima.

Rodríguez Catellanos, Elsa

2004 Situación actual y perspectivas de las editoriales universitarias en Cuba. Seminario Internacional sobre las Editoriales Universitarias hacia el Siglo XXI, América Latina y el Caribe. Caracas: IESALC. Disponible en UNESCO <http://unesdoc.unesco.org/ images/0014/001404/140486s.pdf>.

SagastizÁbal, Leandro de

2006 «Estudio comparativo de las editoriales universitarias de América Latina y el Caribe». En Sagastizábal, Leandro de; Claudio Rama y Richard URIBE. Las editoriales universitarias en América Latina. Bogotá: Centro Regional para el Fomento del Libro en América 
Latina y el Caribe. Cerlalc-Instituto Internacional para la Educación Superior en América Latina y el Caribe. IEsalC, pp. 95-246.

Sierra, Jorge Alfonso

2005 Marketing para editoriales del siglo XXI. San José (Costa Rica): DirecTlibros.

Silva Santisteban, Rocío

2009 «Alas y buen viento». Columna Okupa del diario La República, 6 de diciembre. Disponible en <www.larepublica.pe/columnistas/ kolumna-okupa/alas-y-buen-viento-06-12-2009>. Consulta hecha en $21 / 07 / 2011$.

Universidad Católica Sedes Sapientiae

2009 Presentación. Catálogo del Fondo Editorial UCSS. Elaboración y edición de Patricia Vilcapuma Vinces. Disponible en Portal Universidad Católica Sedes Sapientiae.<www.ucss.edu.pe/fondo/ fondo_presentacion.html>.

Consulta hecha en 21/07/2011.

2008 Manual de estilo del Fondo Editorial UCSS. Elaboración y edición de Patricia Vilcapuma Vinces. Disponible en Portal Universidad Católica Sedes Sapientiae. <www.ucss.edu.pe/fondo/fondo_presentacion. html>. Consulta hecha en 21/07/2011.

Woll, Thomas

2003 Editar para ganar. Estrategias de administración editorial. México, D. F.: Fondo de Cultura Económica. 